Research Paper:

\title{
Knowledge and Attitude of Nurses Working in a Neonatal Intensive Care Unit on the Use of Human Donor Milk
}

\author{
Mahnaz Shoghi $^{1 *}$ (D), Shiva Nazarshodeh ${ }^{1}$, Leili Borimnejad ${ }^{1}$ (iD
}

1. Department of Nursing of Pediatric and Neonatal Intensive Care, Nursing Care Research Center, Faculty of Nursing and Midwifery, Iran University of Medical Sciences, Tehran, Iran.

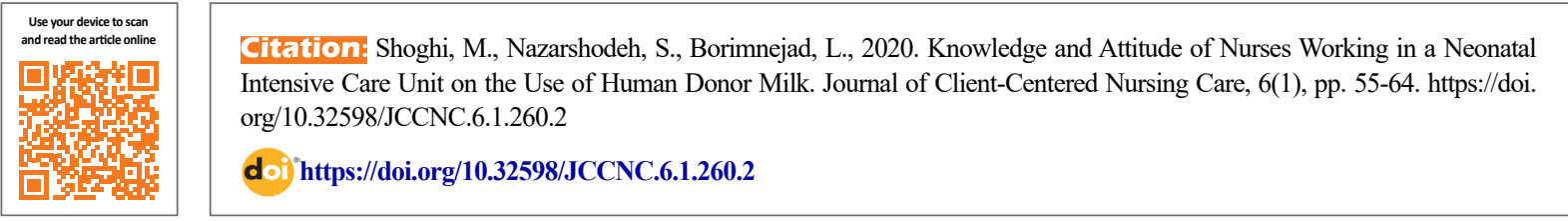

\section{(i) (8)}

Article info:

Received: 05 Oct 2019

Accepted: 03 Jan 2020

Published: 01 Feb 2020
Keywords:

Donor milk, Intensive care unit, Nurses,

Lactation

\begin{abstract}
A B S T RA C T
Background: Donor milk is a newly emerging phenomenon in Iran and its banks are currently operating at a limited level. Nurses' knowledge and attitudes toward this issue play a key role in the adoption of human donor milk by families. This study aimed to determine the knowledge and attitude of nurses working in Neonatal Intensive Care Units (NICUs) regarding the use of human donor milk and its advantages and disadvantages.
\end{abstract}

Methods: This research was a descriptive cross-sectional study. One hundred nurses working in the NICUs of three hospitals affiliated to Iran University of Medical Sciences were recruited by census method. The study data were collected by "nurses' questionnaire towards donor milk and the pros and cons" and "attitude of nurses towards donor milk". The obtained data were analyzed by the independent $t$ test and analysis of variance in SPSS V. 22.

Results: Most nurses had appropriate knowledge about donor milk. About $68 \%$ of them believed that human donor milk would reduce the growth rate of the baby, but $33 \%$ said that the formula milk was easier to find and less stressful than donor milk. Nurses did not express a positive attitude toward donor milk in most questions. Approximately $48 \%$ were opposed to receiving human donor milk. Forty-five percent of the nurses blamed its costs and investment as the strongest barriers toward consuming donor milk in their cities. Around $68 \%$ supported the establishment of a human milk bank in the area or city where they work and reside. The results also showed the knowledge $(\mathrm{P}=0.031)$, and attitude $(\mathrm{P}<0.00)$ of the nurses were significantly associated with their marital status.

Conclusion: The nurses had appropriate knowledge about human donor milk; however, in most cases, they lacked a favorable attitude toward it. It seems that cultural and religious issues might have played a role in this respect.

\section{* Corresponding Author:}

Mahnaz Shoghi, PhD.

Address: Department of Nursing of Pediatric and Neonatal Intensive Care, Nursing Care Research Center, Faculty of Nursing and Midwifery, Iran University of Medical Sciences, Tehran, Iran.

Tel: +98 (912) 3176343

E-mail: shoghi.m@iums.ac.ir 


\section{Highlights}

- The nurses working in neonatal intensive care units had good knowledge about human donor milk.

- The nurses did not have a positive attitude toward human donor milk.

- Knowledge and attitude of the nurses of the neonatal intensive care units about human donor milk were significantly associated with their marital status.

\section{Plain Language Summary}

Human donor milk and donor milk banks are new issues in Iran. Knowledge and attitude of nurses about human donor milk, prepared by human milk banks and its pros and cons are very important because they can encourage mothers to choose donor milk. According to the study results, the nurses working in neonatal intensive care units had good knowledge about donor milk; however, they lacked a favorable attitude toward it. Knowledge and attitude of nurses about donor milk were associated with their marital status, too.

\section{Introduction}

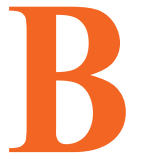

reast milk is the best choice for infants and newborns. No substance can be replaced by breast milk (Alzaree et al., 2019). Breast milk contains all the nutrients necessary for the growth and development of the newborn, and its composition varies according to the associated age and the needs of infants (Ballard \& Morrow 2013). Other benefits of breastfeeding include its constant availability, good temperature, being fresh and free from bacterial contamination, and consequently reduction of the risk of having digestive problems (Di Fabio, Di Natale \& Di Ventura2013; Dogaru et al. 2014).

Breastfeeding is a nutritional standard for babies, but sometimes the conditions for establishing this type of nutrition may not be provided. Some babies need alternative nutritional strategies for various reasons, such as a premature birth (Ahmadi et al., 2016), having metabolic disorders or bowel syndrome, allergies and intolerance to their mother's milk, or special maternal conditions such as infectious diseases, immunological defects, and medicinal regimen, multiple births, breast cancer or any other infectious disease that fails to breastfeed or stop mother breast milk (Merlino-Barr \& Groh-Wargo 2019; Davanzo 2018).

Donor human milk is one of the best substitutes for feeding infants and premature neonates admitted to the Neonatal Intensive Care Units (NICUs) (Bertino et al., 2009). The use of donor milk is associated with biological and clinical benefits for the infant (Merlino-Barr \&
Groh-Wargo 2019; Hanson et al., 2016). Their application is recommended because these kinds of milk cannot be contaminated with cytomegalovirus (De Halleux et al., 2017; Lloyd et al., 2016). On the other hand, the use of this type of milk does not clinically require preparation. Also, it seems that it is better tolerated and digested by infants than the formulated milk, and facilitates the infant's return to mother's milk in the next stages as well (Bertino et al., 2009; Boyd, Quigley \& Brocklehurst 2007, de Halleux et al., 2017).

Today, 120 milk banks have been established in 38 countries, including Serbia, the United States, Canada, India, the Philippines, and China (Colaizy 2016). Recently, 10 hospitals in different cities of Iran have been considered for the establishment of human donor milk banks but only 4 centers are active (Mohamadinasab 2019). The adoption of donor milk and the desire to donate milk to milk banks by mothers and families are heavily dependent on the culture and religious beliefs (Karadag et al., 2015; Pal et al., 2019). Breast milk is considered sacred in Islam, and Muslims believe that much of the mother's attitudes are passed from mother to baby through breast milk. Thus the establishment of donor milk banks in these countries, including Iran, may not be welcomed by mothers and families in need (Gürol, Ozkan \& Celebioğlu 2014; Mortazi 2016).

Knowledge and attitude of nurses about human donor milk, prepared by human milk banks, and the associated pros and cons are very critical (Michaiel et el., 2016; Mackenzie, Javanparast \& Newman 2013). Nurses play a key part in promoting the culture of using donor milk, 
and the use of donor milk instead of using formula milk, or using temporary milk from other breastfeeding mothers. One of the methods that can promote the use and development of milk donation is increasing awareness and knowledge of nurses, and improving the performance of nurses and their information regarding the benefits and disadvantages of using human donor milk. Therefore, we aimed to evaluate the knowledge and attitude of nurses about donor milk and its pros and cons, while the human donor milk banks are newly emerging in Iran.

\section{Materials and Methods}

\section{Design, setting, and sample}

This research was a descriptive cross-sectional study. The study setting included NICUs at three hospitals, affiliated with Iran University of Medical Sciences in Tehran, Iran. A total of 115 nurses were working in the NICUs of these hospitals; among them, 100 nurses participated in this study. The inclusion criteria were having at least a bachelor's degree and a minimum of one year of work experience in the NICU. After distributing 115 questionnaires, 100 nurses completed the questionnaires and finally 100 questionnaires were collected and analyzed.

\section{Instruments}

The questionnaire used in this study had three sections. In the first section, the demographic characteristics of nurses were collected such as age, work experience, marital status, and the number of children. To assess the knowledge of nurses about donor milk, we used the nurses' questionnaire towards donor milk and the pros and cons. This section consisted of 15 questions; score 1 is given to correct answer, and score 0 to incorrect answer (Michaiel et al., 2016). The third section included questions about the attitude of nurses about donor milk. This section had seven questions rated on a 5-point Likert type scale, ranging from "I strongly disagree" to "I very much agree". The very positive attitude in each question was scored 5 , positive attitude 4, neutral attitude 3 , negative attitude 2 , and a very negative attitude scored 1 (Karadag et al. 2015). High scores in both questionnaires were considered as better knowledge and attitude. Also, the questionnaire included four questions about the awareness of nurses about the existence of human donor milk in their city or hospital, participation in workshops about human donor milk, the viewpoints about important barriers to using human donor milk and ideas about the support of human donor banks.

The Cronbach alpha value of the "knowledge of nurses about donor milk pros and cons" and "attitude of nurses about donor milk" questionnaires have been reported as 0.8 and 0.9, respectively (Michaiel et al., 2016; Karadag et al., 2015).

The content validity of the translated versions was assessed by 10 faculty members of the Nursing and Midwifery School of IUMS. The internal consistency reliability in the knowledge section was measured by the Kuder-Richardson method as 0.81 . The reliability of the attitude section was also calculated by the Cronbach alpha as 0.88 .

\section{Data collection}

The list of nurses' names was received from the nurse's directors in each hospital. The nurses who met the inclusion criteria were invited to participate in the study. First, they were informed of research objectives, and after receiving written informed consent, they were assured of the confidentiality of information, and their voluntary participation in the study. Following that, the questionnaires were completed by the subjects via self-reporting. To prevent data contamination, the questionnaires were completed one by one in the presence of the researcher. After completion of each questionnaire, it was briefly reviewed by the researcher and in the case of incompleteness, the participant was requested to answer incomplete questions. These steps were respected until the end of the study and in all clinical research centers.

The participants were also assured that the results of the study would be available in the corresponding hospitals.

\section{Data analysis}

Data analysis was performed in SPSS version 22 by calculating the frequency distribution, mean, and standard deviation in descriptive statistics. To determine the relationship between attitude and knowledge with demographic variables, the ANOVA and the independent $t$ test were used. In this study, the significance level of the tests was considered as 0.05 .

\section{Results}

The nurses' knowledge about donor milk is presented in Table 2. Considering that male personnel could not be employed in NICUs in Iran, all participants were female. About $79 \%$ of the nurses were married. Approximately, $79 \%$ of them had a bachelor's degree in nursing and $15 \%$ had a master's degree (Table 1). According to the results, $68 \%$ of the nurses responded correctly to this question that premature infants feeding with donor milk, have a 
Table 1. Demographic data of the study participants

\begin{tabular}{|c|c|c|c|}
\hline Variable & Group & No. (\%) & Mean \pm SD \\
\hline \multirow{5}{*}{ Age (y) } & $25-29$ & $31(31)$ & \\
\hline & $30-34$ & $24(24)$ & \\
\hline & $35-39$ & $26(26)$ & $33.61 \pm 6.16$ \\
\hline & $40-44$ & $15(15)$ & \\
\hline & 50 & $4(4)$ & \\
\hline \multirow{5}{*}{ Job experience (y) } & $1-5$ & $36(36)$ & \\
\hline & $6-10$ & $24(24)$ & \\
\hline & & & $9.69 \pm 4.7$ \\
\hline & $11-15$ & $27(27)$ & \\
\hline & 16 & $13(13)$ & \\
\hline \multirow{5}{*}{ Job experience in the NICU (y) } & $1-5$ & $47(47)$ & \\
\hline & $6-10$ & $38(38)$ & \\
\hline & & & $4.7 \pm 6.8$ \\
\hline & $11-15$ & $9(9)$ & \\
\hline & 16 & $6(6)$ & \\
\hline
\end{tabular}

Client- Centered Nursing Care

lower growth rate than infants fed with breast milk. About $33 \%$ said that the accessibility to infant formula was easier, and its consumption was less stressful than donor milk.

As Table 3 presents, about $76 \%$ of the nurses were opposed to receiving breast milk from other mothers, and $48 \%$ were opposed to receiving human donor milk. Approximately, $40 \%$ of them expressed their willingness to donate their milk to milk banks, and $51 \%$ believed that if the mother was unable to breastfeed or prohibited to breastfeed her baby, they would suggest the human milk as the first suitable alternative to the family (Table 3 ).

The results of the analysis of four extra questions revealed that $52 \%$ of the nurses have stated that there were not any donor milk banks in their area or city of work or residence, and $46 \%$ were unaware of the existence of a donor milk bank in their city and location of residence. Forty-five percent of the nurses declared that the costs and investment in this field are the strongest barriers for not using the donor milk in their area. After costs, the parents' preferences, availability of milk banks, supplier preferences, and preparation for consumption, were the other obstacles for non-use of donor milk. About 85\% of the nurses had not participated in a human donor milk workshop or training course; about $68 \%$ of them believed that they will support the establishment of a human donor milk bank in the area or their city of residence.

According to Tables 4 and 5, the knowledge of nurses was significantly associated with their marital status. Besides, the knowledge of nurses was significantly correlated with having and not having a child. The attitude of nurses was significantly related to their marital status.

\section{Discussion}

This study aimed to determine the knowledge and attitude of nurses, working in the NICUs, about the use of donor milk and its associated advantages and disadvantages. According to the results, NICUs nurses had relatively good knowledge of donor milk. However, about one-third of them believed that breastfeeding was different, compared with the donor milk, and the children fed with donor milk have a lower growth rate, in comparison to the infants fed with breast milk. In addition, about one-third of them thought that compared to donor milk, feeding a baby with formula milk was easier and less stressful for mothers. More than half of them stated that donor milk, in comparison with formula, reduces the risk of necrotizing enterocolitis and newborns infections. Hospitalization duration in NICU for the newborns fed with donor milk and breast milk is less than that of feeding with formula. Ac- 
Table 2. The Knowledge of nurses regarding donor milk

\begin{tabular}{|c|c|c|c|}
\hline \multirow{2}{*}{ Questions } & \multicolumn{2}{|c|}{ No. (\%) } & \multirow{2}{*}{ Mean \pm SD } \\
\hline & Correct & Incorrect & \\
\hline $\begin{array}{l}\text { 1. Preterm infants who are breastfed have lower rates of necrotizing entero- } \\
\text { colitis than those infants who receive infant formula. }\end{array}$ & $94(94)$ & $6(6)$ & $0.94 \pm 0.23$ \\
\hline $\begin{array}{l}\text { 2. Preterm infants who are breastfed have lower rates of infection than those } \\
\text { infants who receive infant formula. }\end{array}$ & 97 (97) & $2(2)$ & $0.98 \pm 0.140$ \\
\hline $\begin{array}{l}\text { 3. Preterm infants who are breastfed have improved feeding tolerance, com- } \\
\text { pared to those infants who receive infant formula. }\end{array}$ & $98(98)$ & $3(3)$ & $0.97 \pm 0.171$ \\
\hline $\begin{array}{l}\text { 4. Preterm infants, receiving donor human milk have lower rates of necrotiz- } \\
\text { ing enterocolitis than those infants receiving infant formula. }\end{array}$ & 87 (87) & $13(13)$ & $0.87 \pm 0.338$ \\
\hline $\begin{array}{l}\text { 5. Preterm infants, receiving donor human milk have lower rates of infection } \\
\text { than infants receiving infant formula. }\end{array}$ & $86(86)$ & $14(14)$ & $0.87 \pm 0.3$ \\
\hline $\begin{array}{l}\text { 6. Preterm infants, receiving donor human milk have improved feeding toler- } \\
\text { ance, compared with those receiving infant formula. }\end{array}$ & $85(85)$ & $15(15)$ & $0.86 \pm 0.17$ \\
\hline $\begin{array}{l}\text { 7. Preterm infants, receiving donor human milk, have lower rates of growth, } \\
\text { compared with those infants receiving mother's breast milk. }\end{array}$ & $62(62)$ & $38(38)$ & $0.97 \pm 0.35$ \\
\hline $\begin{array}{l}\text { 8. Preterm infants receiving donor human milk have lower rates of growth, } \\
\text { compared with those infants receiving infant formula. }\end{array}$ & $82(82)$ & $18(18)$ & $0.82 \pm 0.48$ \\
\hline $\begin{array}{l}\text { 9. Preterm infants who are given breast milk (mother's own or donor milk) } \\
\text { have longer hospitalizations/NICU stays, compared with those infants receiv- } \\
\text { ing preterm formula. }\end{array}$ & $88(88)$ & $12(12)$ & $0.88 \pm 0.22$ \\
\hline $\begin{array}{l}\text { 10. Donor breast milk should be the first-line alternative when breastfeeding } \\
\text { is indicated, but mother's supply is insufficient or unavailable. }\end{array}$ & $67(67)$ & $33(33)$ & $0.67 \pm 0.47$ \\
\hline $\begin{array}{l}\text { 11. Feeding with donor milk is an easier and less stressful method for mothers } \\
\text { than formula milk. }\end{array}$ & $67(67)$ & $33(33)$ & $0.67 \pm 0.47$ \\
\hline 12. Human donor milk is more nutritious than formula milk. & $77(77)$ & $23(23)$ & $0.77 \pm 0.44$ \\
\hline 13. Feeding newborns with human milk is a convenient nutritional method. & $69(69)$ & $31(31)$ & $0.69 \pm 0.46$ \\
\hline 14. Feeding newborns with human donor milk will save you money. & $73(73)$ & $27(27)$ & $0.73 \pm 0.44$ \\
\hline $\begin{array}{l}\text { 15. In my opinion, feeding of infants with human donor milk is a natural way } \\
\text { of nourishing infants. }\end{array}$ & $75(75)$ & $25(25)$ & $0.75 \pm 0.43$ \\
\hline Total Mean $\pm S D$ & & $11.37 \pm 2.8$ & \\
\hline
\end{tabular}

Table 3. The attitude of nurses toward human donor milk

\begin{tabular}{|c|c|c|c|c|c|c|}
\hline \multirow[b]{2}{*}{ Content } & \multicolumn{5}{|c|}{ No. (\%) } & \multirow[b]{2}{*}{ Mean $\pm S D$} \\
\hline & $\begin{array}{l}\text { Strongly } \\
\text { Disagree }\end{array}$ & Disagree & No Idea & Agree & $\begin{array}{c}\text { Strongly } \\
\text { Agree }\end{array}$ & \\
\hline $\begin{array}{l}\text { What is your opinion about feeding your } \\
\text { baby with breast milk of another woman, } \\
\text { who you know, when you do not have } \\
\text { sufficient breast milk? }\end{array}$ & $40(40)$ & $36(36)$ & $7(7)$ & $16(16)$ & $1(1)$ & $2.02 \pm 1 / 1$ \\
\hline $\begin{array}{c}\text { What is your opinion about feeding your } \\
\text { baby with breast milk from another } \\
\text { woman, who you do not know (milk } \\
\text { bank), when you do not have sufficient } \\
\text { breast milk? }\end{array}$ & $22(22)$ & $26(26)$ & 14 (14) & 37 (37) & $1(1)$ & $2.69 \pm 1.2$ \\
\hline $\begin{array}{l}\text { What is your idea about giving the breast } \\
\text { milk that your baby does not need to } \\
\text { some other babies, who you know? }\end{array}$ & $30(30)$ & $29(29)$ & $17(17)$ & $20(20)$ & $4(4)$ & $2.39 \pm 1.2$ \\
\hline $\begin{array}{l}\text { What is your idea about giving the breast } \\
\text { milk that your baby does not need hu- } \\
\text { man milk banks? }\end{array}$ & $13(13)$ & $25(25)$ & $22(22)$ & $33(33)$ & $7(7)$ & $2.69 \pm 1.17$ \\
\hline
\end{tabular}




\begin{tabular}{|c|c|c|c|c|c|c|}
\hline \multirow[b]{2}{*}{ Content } & \multicolumn{5}{|c|}{ No. (\%) } & \multirow[b]{2}{*}{ Mean $\pm S D$} \\
\hline & $\begin{array}{l}\text { Strongly } \\
\text { Disagree }\end{array}$ & Disagree & No Idea & Agree & $\begin{array}{l}\text { Strongly } \\
\text { Agree }\end{array}$ & \\
\hline $\begin{array}{l}\text { What do you think about the use of hu- } \\
\text { man donor milk as the first choice if you } \\
\text { cannot breastfeed? }\end{array}$ & $14(14)$ & $21(21)$ & $21(21)$ & $41(41)$ & $3(3)$ & $2.98 \pm 1.14$ \\
\hline $\begin{array}{l}\text { What is your opinion about the use of } \\
\text { breast milk of other mothers to mothers } \\
\text { who are admitted to the same ward as } \\
\text { you, and do not have sufficient milk? }\end{array}$ & $29(29)$ & $38(38)$ & $17(17)$ & $14(14)$ & $2(2)$ & $2.22 \pm 1.07$ \\
\hline $\begin{array}{l}\text { What is your opinion about the use of } \\
\text { human donor milk for feeding a baby ad- } \\
\text { mitted to your ward, as your first choice? }\end{array}$ & $12(12)$ & $17(17)$ & $20(20)$ & $45(45)$ & $6(6)$ & $3.16 \pm 1.52$ \\
\hline Total Mean $\pm S D$ & \multicolumn{5}{|c|}{$18.42 \pm 5.77$} & \\
\hline
\end{tabular}

cording to the results, the nurses working in NICUs had appropriate knowledge of donor milk, as evidence shows that use of donated milk decreases the risk of necrotizing enterocolitis, infection and the duration of the newborn's hospitalization in the NICU (de Halleux et al., 2017; Kantorowska et al., 2016; Valentine et al.. 2019).

Consistent with the study results, nurses' knowledge about donor milk in most studies has been reported as desirable (Michaiel et al., 2016; Lam, Kecskés \& AbdelLatif 2012). Carroll et al. with different findings reported that the knowledge of the clinical team in the NICU is not enough regarding donor human milk and its associated harmfulness and benefits (Carroll \& Herrmann 2012). Another study has shown that the health care team has a good knowledge of breast milk, but have not appropriate information about human donor milk (Hahn et al., 2017).

Other studies indicate the importance of nurses' knowledge of donor milk. Mothers are rarely aware of donor milk and know nothing about the contents of this kind of milk and its associated risks and disadvantages. Mothers believed that higher awareness among nurses and receiving information from the clinical team plays a crucial role in

Table 4. Mean and standard deviation of knowledge of nurses towards donor milk with respect to demographic variables

\begin{tabular}{|c|c|c|c|}
\hline Variables & Group & Mean $\pm S D$ & Statistical Test \\
\hline \multirow{4}{*}{ Age $(y)$} & $25-29$ & $11.64 \pm 3.6$ & \multirow{4}{*}{$\begin{array}{l}F=0.645 \\
P=0.588\end{array}$} \\
\hline & $30-34$ & $11.70 \pm 3.7$ & \\
\hline & $35-39$ & $12.38 \pm 2.9$ & \\
\hline & & $12.07 .63 \pm 2.4$ & \\
\hline \multirow{2}{*}{ Marital status } & Single and widow & $27.1 \pm 3.4$ & \multirow{2}{*}{$\begin{array}{l}t=2.185 \\
P=0.031\end{array}$} \\
\hline & Married & $11.72 \pm 3.1$ & \\
\hline \multirow{4}{*}{ Job experience (y) } & & $11.19 \pm 3.5$ & \multirow{4}{*}{$\begin{array}{l}F=1.356 \\
P=0.261\end{array}$} \\
\hline & $6-10$ & $12.58 \pm 3.5$ & \\
\hline & $11-15$ & $12.48 \pm 2.8$ & \\
\hline & & $12.69 \pm 2.6$ & \\
\hline \multirow{3}{*}{$\begin{array}{l}\text { Job experience in the } \\
\text { NICU (y) }\end{array}$} & & $11.91 \pm 3.4$ & \multirow{3}{*}{$\begin{array}{l}F=0.102 \\
P=0.903\end{array}$} \\
\hline & $6-10$ & $12.2 \pm 3.2$ & \\
\hline & & $12.1 \pm 2.8$ & \\
\hline \multirow{2}{*}{ Educational level } & BSN & $12.2 \pm 3.2$ & \multirow{2}{*}{$\begin{array}{l}t=0.941 \\
P=0.349\end{array}$} \\
\hline & MSN & $11.33 \pm 3.5$ & \\
\hline
\end{tabular}


Table 5. Nurses' attitudes toward donor milk with respect to demographic variables

\begin{tabular}{|c|c|c|c|}
\hline \multirow{2}{*}{ Variable } & \multicolumn{2}{|c|}{ Attitudes Toward Donor Milk (Mean) } & \multirow{2}{*}{ Statistical Test } \\
\hline & Group & Mean \pm SD & \\
\hline \multirow{4}{*}{$\begin{array}{l}\text { Age } \\
\text { (y) }\end{array}$} & $25-29$ & $23.35 \pm 5.25$ & \multirow{4}{*}{$\begin{array}{l}F=0.235 \\
P=0.872\end{array}$} \\
\hline & $30-34$ & $23.66 \pm 4.49$ & \\
\hline & $35-39$ & $28.84 \pm 4.04$ & \\
\hline & & $22.63 \pm 4.51$ & \\
\hline \multirow{2}{*}{ Marital status } & Single and widow & $27.1 \pm 4.9$ & \multirow{2}{*}{$\begin{array}{l}t=4.561 \\
P<0.00\end{array}$} \\
\hline & Married & $22.23 \pm 3.9$ & \\
\hline \multirow{4}{*}{$\begin{array}{l}\text { Job experience } \\
\text { (y) }\end{array}$} & \multirow{4}{*}{$\begin{array}{r}6-10 \\
11-15\end{array}$} & $22.72 \pm 4.6$ & \multirow{4}{*}{$\begin{array}{l}F=1.944 \\
P=0.149\end{array}$} \\
\hline & & $24.25 \pm 4.7$ & \\
\hline & & $22.7 \pm 4.3$ & \\
\hline & & $22.30 \pm 4.8$ & \\
\hline \multirow{3}{*}{ Job experience in the NICU (y) } & \multirow{3}{*}{$6-10$} & $24.1 \pm 4.9$ & \multirow{3}{*}{$\begin{array}{l}F=1.944 \\
P=0.149\end{array}$} \\
\hline & & $22.2 \pm 3.9$ & \\
\hline & & $22.5 \pm 4.6$ & \\
\hline \multirow{2}{*}{ Educational level } & BSN & $22.97 \pm 4.7$ & \multirow{2}{*}{$\begin{array}{c}t=0.95 \\
P=0.344\end{array}$} \\
\hline & MSN & $24.2 \pm 3.8$ & \\
\hline
\end{tabular}

selecting this nutritional method (Mackenzie, Javanparast, \& Newman 2013; Pal et al., 2019). It has been reported in a qualitative study that even though donor milk banks in South Australia are rare, lactating mothers considered milk donation very easy and not very time-consuming. Mothers of newborns in need of donor milk also expressed that in the case of the reassurance of the health care team, and lack of contamination of donor milk, they tend to adopt it as an alternative (Mackenzie, Javanparast \& Newman 2013).

The results of our study showed that despite proper knowledge, the nurses lacked a positive attitude toward donor milk in many aspects. About half of them were opposed to feeding their babies with donor milk and 35\% of them still opposed, even though donor milk after breast milk should be considered as the first preferred nutritional method for the baby. Approximately one-third of them disagreed with the donation of milk to milk banks and more than half of them did not show any desire for giving their breast milk to mothers inside the ward. Only about half of them stated that if the mother was not able to breastfeed, they would introduce this method as the first alternative. However, in some other countries, nurses' attitudes about suggesting donating milk to families were better than ours (Michaiel et al., 2016; Lam, Kecskés \& Abdel-Latif 2012).

The absence of extensive use of human donor milk in Iran, and lack of experience in its application, might have affected the attitude of nurses in our study (Mortazi
2016). As Hahn considers, the small number of donor milk banks in Korea is one of the reasons for the attitude and viewpoint of nurses in this regard (Hahn et al., 2017).

It has been shown that the majority of milk donating mothers are against accepting the milk for their children. Other mothers also believe that they would receive donor milk, only if the donor is one of their close relatives. Concern about diseases, fear of transferring traits and genetic characteristics, and cultural and religious taboos were among the most important reasons for mother's disapproval of donor milk (Ighogboja et al., 1995). It seems that in the case of donating breast milk, the religious and cultural beliefs of women in different countries should be taken into account (Gürol, Ozkan \& Celebioğlu 2014). Different religions and cultures may have diverse views on this issue (Fallah Tafti 2016; Velayati et al., 2016; Gürol, Ozkan \& Celebioğlu 2014; Mortazi 2016; Ergin \& Uzun 2018).

According to our results, more than half of the nurses have stated that donor milk banks do not exist in their area or city of work. It should be noted that only two nurses confirmed the presence of donor milk banks in the city, where they work or reside. However, as a study in Turkey showed, nurses were more aware of the donor human milk banks and how to access them (Michaiel et al., 2016).

However, consistent with our results, the results of another study in Korea showed that nurses had little infor- 
mation about human donor milk centers in their workplace and place of residence (Hahn et al., 2017). It should be noted that the donor human milk bank in Iran is a newly established center and its activities are very limited and only three donor human milk banks are active. Therefore, it seems that the lack of information of participants in this study about these centers results from the lack of widespread use of human donor milk at the hospitals and the limited availability of human donor milk banks in Iran. However, providing information in this regard to nurses seems necessary (Mohamadinasab 2019).

Nearly half of the nurses mentioned the costs of donor milk as the most important obstacle for not using donor milk in their region. After costs, parents' preference, access to the milk bank, supplier preferences, and preparation for consumption, were the most important barriers for the use of donor milk. This is not congruent with other studies on the cost of donor milk. In the studies conducted, the issue of comparing the cost of donor milk and formula milk shows that the use of donor milk is much less costly and easier to access (Assad, Elliott \& Abraham 2016; Trang et al., 2018). These conditions require appropriate implementation solutions for the supply, processing, and distribution of donor milk (Gürol, Ozkan \& Celebioğlu 2014).

According to our results, more than half of the nurses said that they will support the establishment of a human donor milk bank in their area or city of residence. Other studies have also shown that nurses are eager to support human donor milk, and their support level was higher than the nurses of our study (Michaiel et al. 2016; Lam, Kecskés, \& Abdel-Latif 2012). This difference may be due to the extensive inaccessibility of our nurses to human donor milk banks. Lack of experience and uncertainty about their role in supporting this issue might have affected their perspectives, too. However, in this study and most of their statements, the nurses did not express a favorable attitude towards human donor milk, which could have also reduced their tendency to support and introduce this option to mothers. Perhaps the close familiarity of nurses with these centers, and their practical training, explaining and clarifying the religious and holy aspects of the human donor milk could change the attitude of nurses about this concept, and increase their support of this issue. As the study on mothers demonstrates, it is important to have a brief understanding of the donor milk bank and the way it works, to increase their willingness to support these centers (Gürol, Ozkan \& Celebioğlu 2014).
The results showed that single nurses had higher knowledge scores about donor milk, compared with married nurses. This finding has not been evaluated in other studies; however, single nurses were younger and fresher than married nurses, and this might have affected their level of knowledge.

On the other hand, single nurses had a more positive attitude toward donor milk than married nurses did. In justifying this finding, it can be said that the views of post-marital individuals about parenting and its related issues are very much influenced by the context and culture of the couple's family. So maybe after the marriage, the people take this issue more seriously, and this can affect their attitude, compared with the pre-marriage state (Ergin \& Uzun 2018).

It is recommended that studies be conducted to determine the factors affecting the use and non-use of human donor milk among nurses. Assessment of the effectiveness of educational workshops on the knowledge and attitudes of nurses about human donor milk is also suggested in future studies.

Considering that in this study, the knowledge and attitudes of nurses were studied, it is suggested that studies be carried out to interdisciplinary evaluate the attitude of nurses with respect to religious and jurisprudential aspects in the field of human donor milk.

Nurses' knowledge about donor milk was appropriate, and they had an acceptable level of knowledge in this regard, but their attitude toward donor milk and donor milk banks was not positive. It seems that educating more nurses about human donor milk and their familiarity with its nutritional benefits for newborns, and solving the religious and cultural problems in this field, could be effective in changing their views and attitudes about human donor milk and milk banks, and increase the use of this kind of milk.

\section{Ethical Considerations}

\section{Compliance with ethical guidelines}

Institutional Review Board approval was obtained from the Iran University of Medical Sciences before the initiation of the study (Ethical Code: IR.IUMS.REC 1395.9311451001). Before data collection, the researcher informed the participants and obtained their written consent. 


\section{Funding}

This paper extracted from MSc. thesis of Shiva Nazarshodeh, Department of Pediatric and intensive Neonatal Nursing Department, Iran University of Medical Sciences. This research was supported by Iran University of Medical Sciences (IR.IUMS.REC 1395.9311451001).

\section{Authors' contributions}

All authors were equally contributed in preparing this article

\section{Conflict of interest}

The authors declared no conflict of interest.

\section{Acknowledgments}

We would like to thank all the participants in this study, and the research Centers of the Hospitals of Akbar Abadi, Ali Asghar, Hazrat Rasoul Akram, for their cooperation in conducting this study.

\section{References}

Ahmadi, Z., et al., 2016. Comparing the social support which fathers and mothers of preterm infants receive in the neonatal intensive care units. Journal of Client-Centered Nursing Care, 2(2), pp. 83-8. [DOI:10.32598/jccnc.2.2.83]

Alzaree, F. A., et al., 2019. Effect of early breast milk nutrition on serum insulin-like growth factor-1 in preterm infants. Open Access Macedonian Journal of Medical Sciences, 7(1), pp. 77-81. [DOI:10.3889/oamjms.2019.035] [PMID] [PMCID]

Assad, M., Elliott, M. J., \& Abraham, J. H., 2016. Decreased cost and improved feeding tolerance in VLBW infants fed an exclusive human milk diet. Journal of Perinatology, 36(3), pp. 216-20. [DOI:10.1038/jp.2015.168] [PMID]

Ballard, O., \& Morrow, A. L., 2013. Human milk composition: Nutrients and bioactive factors. Pediatric Clinics of North America, 60(1), pp. 49-74. [DOI:10.1016/j.pcl.2012.10.002] [PMID] [PMCID]

Bertino, E., et al., 2009. Benefits of donor human milk for preterm infants: Current evidence. Early Human Development, 85(10 Suppl), pp. S9-10. [DOI:10.1016/j.earlhumdev.2009.08.010] [PMID]

Boyd, C. A., Quigley, M. A., \& Brocklehurst, P., 2007. Donor breast milk versus infant formula for preterm infants: Systematic review and meta-analysis. Archives of Disease in Childhood-Fetal and Neonatal Edition, 92(3), pp. F169-75. [DOI:10.1136/adc.2005.089490] [PMID] [PMCID]

Carroll, K., \& Herrmann, K., 2012. Introducing donor human milk to the NICU: Lessons for Australia. Breastfeeding Review, 20(3), pp. 19-26. [PMID]
Colaizy, T. T., 2016. Donor human milk for preterm infants: What it is, what it can do, and what still needs to be learned. Clinics in Perinatology, 41(2), pp. 437-50. [DOI:10.1016/j.clp.2014.02.003] [PMID]

Davanzo, R., 2018. Controversies in breastfeeding. Frontiers in Pediatrics, 6, p. 278. [DOI:10.3389/fped.2018.00278] [PMID] [PMCID]

de Halleux, V., et al., 2017. Use of donor milk in the neonatal intensive care unit. Seminars in Fetal and Neonatal Medicine, 22(1), pp. 23-9. [DOI:10.1016/j.siny.2016.08.003] [PMID]

Di Fabio, S., Di Natale, C., \& Di Ventura, L., 2013. Human milk in the neonatal intensive care unit: Good practices. Early Human Development, 89(4), pp. S119-20. [DOI:10.1016/S0378-3782(13)701257]

Dogaru, C. M., et al., 2014. Breastfeeding and childhood asthma: Systematic review and meta-analysis. American Journal of Epidemiology, 179(10), pp. 1153-67. [DOI:10.1093/aje/kwu072] [PMID]

Ergin, A., \& Uzun, S. U., 2018. Turkish women's knowledge, attitudes, and behaviors on wet-nursing, milk sharing and human milk banking. Maternal and Child Health Journal, 22(4), pp. 454-60. [DOI:10.1007/s10995-018-2433-1] [PMID]

Fallah Tafti, F., 2016. [A comparative study of in Islamic religious sentence milk bank (Persian)]. Islamic Jurisprudence Research, 12(1), pp. 111-36. [DOI:10.22059/JORR.2016.58017]

Gürol, A., Ozkan, H., \& Celebioğlu, A., 2014. Turkish women's knowledge and views regarding mother's milk banking. Collegian, 21(3), pp. 239-44. [DOI:10.1016/j.colegn.2013.05.002] [PMID]

Hahn, W. H., et al., 2017. A survey on the awareness of human milk bank in Korean female health care providers. Perinatology, 28(1), pp. 11-9. [DOI:10.14734/PN.2017.28.1.11]

Hanson, C., et al., 2016. A comparison of nutritional antioxidant content in breast milk, donor milk, and infant formulas. Nutrients, 8(11), p. 681. [DOI:10.3390/nu8110681] [PMID] [PMCID]

Ighogboja, I. S., et al., 1995. Mothers' attitudes towards donated breastmilk in Jos, Nigeria. Journal of Human Lactation, 11(2), pp. 93-6. [DOI:10.1177/089033449501100211] [PMID]

Kantorowska, A., et al., 2016. Impact of donor milk availability on breast milk use and necrotizing enterocolitis rates. Pediatrics, 137(3), p. e20153123. [DOI:10.1542/peds.2015-3123] [PMID] [PMCID]

Karadag, A., et al., 2015. Human milk banking and milk kinship Perspectives of mothers in a Muslim country. Journal of Tropical Pediatrics, 61(3), pp. 188-96. [DOI:10.1093/tropej/fmv018] [PMID]

Lam, E. Y., Kecskés, Z., \& Abdel-Latif M. E., 2012. Breast milk banking: Current opinion and practice in Australian neonatal intensive care units. Journal of Paediatrics and Child Health, 48(9), pp. 833-9. [DOI:10.1111/j.1440-1754.2012.02530.x] [PMID]

Lloyd, M. L., et al., 2016. Inactivation of cytomegalovirus in breast milk using ultraviolet-C irradiation: Opportunities for a new treatment option in breast milk banking. PLoS One, 11(8), p. e0161116. [DOI:10.1371/journal.pone.0161116] [PMID] [PMCID]

Mackenzie, C., Javanparast, S., \& Newman, L., 2013. Mothers knowledge of and attitudes toward human milk banking in South Australia: A qualitative study. Journal of Human Lactation, 29(2), pp. 222-9. [DOI:10.1177/0890334413481106] [PMID] 
Merlino-Barr, S., \& Groh-Wargo, S., 2019. Donor breast milk for the preterm infant: Your questions answered! Neonatal Network, 38(1), pp. 7-16. [DOI:10.1891/0730-0832.38.1.7] [PMID]

Michaiel, G., et al., 2016. Health practitioners knowledge, beliefs, and attitudes regarding the useof donor human milk in neonatal intensive care. Maternal and Pediatric Nutrition, 2(2). [DOI:10.4172/2472-1182.1000108]

Mohamadinasab, M., 2019. The opening of the first donor milk bank in Iran. Fars State: Tansim News. Cited 2 Aug 2019. https:/ / www. tasnimnews.com/fa/news/1398/05/11/2067411/.08/2/2019ed

Mortazi, A., 2016. [Research on the history and necessity of establishing breast milk banks, and related jurisprudential and legal challenges (Persian)]. Journal of Medical Ethics and History of Medicine, 8(5), pp. 55-68. http://ijme.tums.ac.ir/article-1-5636-en.html

Pal, A., et al., 2019. Attitudes towards Donor Breast Milk in an Inner City Population. International Journal of Pediatrics, 2019. [DOI:10.1155/2019/3847283] [PMID] [PMCID]

Trang, S., et al., 2018. Cost-effectiveness of supplemental donor milk versus formula for very low birth weight infants. Pediatrics, 141(3), p. e20170737. [DOI:10.1542/peds.2017-0737] [PMID]

Valentine, G. C., et al., 2019. 937: Decreased rates of necrotizing enterocolitis associated with exclusive human milk-based diet. American Journal of Obstetrics \& Gynecology, 220(1), pp. S603-4. [DOI:10.1016/j.ajog.2018.11.961]

Velayati, M., 2016. Jurisprudential study of milk bank based on nutritional parameters, formula of combination of mothers' milk and immunological and physiological mechanisms of medicine. Advances in Food Science and Technology, 8(2), pp. 123-33. https:// www.cabdirect.org/cabdirect/abstract/20173296666 